\title{
QUANTIFYING PHYSICAL AND PSYCHOLOGICAL IMPACTS OF EXPLOSIVE ATTACKS ON BUILDING OCCUPANTS
}

\author{
STEVEN SCHULDT $^{1}$, AHMET SOYLEMEZOGLU ${ }^{2}$, NOAH GARFINKLE ${ }^{2} \&$ KHALED EL-RAYES ${ }^{3}$ \\ ${ }^{1}$ Department of Systems Engineering and Management, Air Force Institute of Technology, USA \\ ${ }^{2}$ US Army Corps of Engineers, Engineer Research and Development Center, Construction Engineering \\ Research Laboratory, USA \\ ${ }^{3}$ Department of Civil and Environmental Engineering, University of Illinois at Urbana-Champaign, USA
}

\begin{abstract}
Personnel suffer devastating physical and psychological impacts from explosive terrorist attacks targeting buildings. Explosive attacks produced 42,972 casualties in 2017 alone and survivors of terrorist attacks experience post-traumatic stress disorder (PTSD) at rates as high as $40 \%$. Designers use three primary strategies to protect buildings and their occupants against explosive terrorist attacks: (1) maximize the distance between a building and where an explosive can be easily placed; (2) construct perimeter blast walls; and (3) employ blast-resistant building materials. This paper presents a personnel impact assessment model capable of efficiently quantifying physical and psychological impacts experienced by the occupants of buildings damaged by explosive attacks. The model provides a comprehensive analysis of significant personnel impacts, including fatalities, serious injuries, minor injuries, and occurrences of PTSD. Model performance was evaluated using case studies of single and multi-building sites, and the results illustrated the model's expediency and flexibility. These capabilities are expected to assist building designers in their critical task of analyzing and selecting the design strategy that minimizes the security risks to site personnel from the threat of explosive terrorist attacks. Keywords: blast effects, consequence, post-traumatic stress disorder, injury, terrorism.
\end{abstract}

\section{INTRODUCTION}

Personnel suffer devastating physical and psychological impacts from explosive terrorist attacks targeting buildings. In 2017 alone, explosive attacks resulted in 42,972 casualties worldwide, $74 \%$ of which were civilians [1]. The survivors of these terrorist attacks experience emotional and psychological disorders, including post-traumatic stress disorder, at rates as high as $40 \%$ [2], [3]. Building designers can significantly reduce facility damage and the likelihood of occupant casualties caused by an explosive attack by incorporating three main design strategies. The most effective design strategy is maximizing the standoff distance between a building and the likely location of an explosive. If additional space is not available, perimeter blast walls can be constructed to reduce blast loads on the building and provide fragmentation protection. The final design strategy is building hardening [4]. Building designers require a method to accurately and efficiently evaluate all feasible design alternatives in order to select the design configuration that minimizes the security risks to building occupants from the threat of explosive terrorist attacks.

Numerous research studies have analyzed the frequency and severity of fatalities, injuries, and psychological impacts from recent historical terrorist attacks, including the 1995 Oklahoma City bombing [5], [6]; the 1998 US Embassy bombing in Nairobi, Kenya [7], [8]; the September 11th attack on New York City, 2001 [9], [10]; and the 2004 Madrid, Spain train bombing [11], [12]. Victims of explosive attacks experience fatalities and several common injury types, including severe head trauma [13]; lung [14], ear [15], and eye [16] damage, as well as lacerations and other injuries caused by flying glass debris [17]. Additionally, victims and bystanders of these attacks were diagnosed with myriad emotional 
and psychological disorders, including PTSD, major depression, panic disorder, agoraphobia, generalized anxiety disorder, and alcohol use disorder.

Several other studies produced models that optimize site layout planning in order to protect buildings and increase site security [18]-[20]. Notably, Schuldt and El-Rayes (2018) developed a multi-objective optimization model that selects the site layout, blast wall type, and building material that presents the optimal trade-off between minimizing building destruction levels and minimizing site construction costs [21]. Despite their significant contributions, these studies do not: (1) efficiently quantify the expected number of fatalities and injuries suffered by building occupants from an explosive attack; and (2) predict the extent of psychological impacts among explosive attack survivors. Accordingly, this paper presents the development of a personnel impact assessment model capable of efficiently quantifying physical and psychological impacts experienced by the occupants of buildings damaged by explosive attacks.

\section{PERSONNEL IMPACT ASSESSMENT MODEL FORMULATION}

This section presents the formulation of a personnel impact assessment model. Model development is accomplished in the following three steps: (1) identifying model input parameters; (2) quantify physical impacts, including fatalities, serious, and minor injuries on building occupants; and (3) calculating psychological impacts on attack survivors.

\subsection{Input parameters}

In order to quantify the effects of explosive attacks on building occupants, the model must first calculate blast damage levels of buildings and account for changes in the three aforementioned protection strategies. Accordingly, the model utilizes three main types of input parameters: (1) explosive parameters - blast charge weight $(\mathrm{kg})$ and location of the explosive; (2) blast wall parameters - location of the blast wall, blast wall material, and blast wall height (m); and (3) building parameters - number of building occupants, building material, building geometry, location of the building and its orientation as shown in Fig. 1.

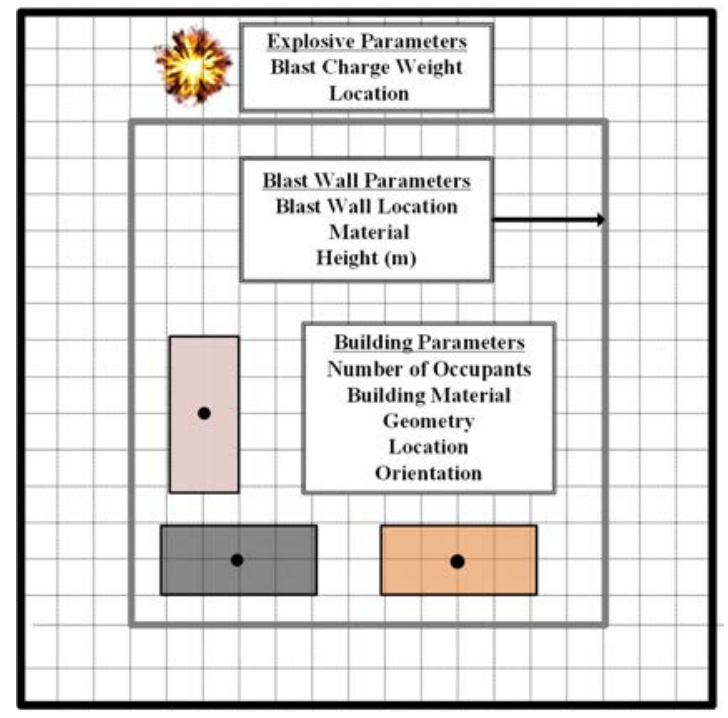

Figure 1: Model input parameters. 
The model uses a grid system with a user-defined grid interval to specify explosive, blast wall, and building locations. Buildings locations are established by the placement of their centroid on the grid system and building orientation is the degree of rotation about the centroid. Building occupants are assumed to be uniformly distributed within each building. Furthermore, occupants are assigned to a building based upon the prorated amount of time they spend within a building each day. For example, if an individual was assigned to a site where they both lived and worked, a typical work day may be allotted as follows: 12 hours in their residence, 8 hours in their office building, 2 hours in a dining facility, 1 hour in a fitness center, and 1 hour commuting, corresponding to a prorated occupancy of $0.5,0.33$, $0.08,0.04$, and 0.04 , respectively.

The present model utilizes a recently developed method for quantifying blast effects on buildings behind blast walls in order to compute the percentage of a building within five specified damage levels: minimal, minor, moderate, heavy, and severe, and to calculate the total percent building destruction [22]. The present model uses these percentages to quantify the physical and psychological impacts on building occupants.

\subsection{Quantify physical impacts}

Physical impacts of explosive attacks include fatalities, serious injuries, and minor injuries. The prevalence of each injury type is quantified by multiplying the aforementioned percentage of a building within the five specified damage levels $\left(B A_{l}\right)$ by the number of building occupants and the appropriate injury ratio, which is the percentage of occupants expected to suffer each injury type within each damage level $\left(P_{l}^{F}, P_{l}^{S I}\right.$, and $P_{l}^{M I}$ for fatalities, serious injuries, and minor injuries, respectively), as shown in eqns (1)-(3).

$$
\begin{gathered}
F=\sum_{l=1}^{5} B A_{l} \times O \times P_{l}^{F}, \\
S I=\sum_{l=1}^{5} B A_{l} \times O \times P_{l}^{S I}, \\
M I=\sum_{l=1}^{5} B A_{l} \times O \times P_{l}^{M I},
\end{gathered}
$$

where,

$F=$ number of expected building occupant fatalities;

$l=$ facility damage level, where $1=1,2,3,4,5$ represents minimal, minor, moderate, heavy, and severe damage, respectively;

$B A_{l}=$ percent building area within damage level (1);

$O=$ prorated number of building occupants;

$P_{l}^{F}=$ percentage of occupant fatalities expected within damage level (1);

$S I=$ number of building occupants expected to suffer serious injuries;

$P_{l}^{S I}=$ percentage of occupants expected to suffer serious injuries within damage level (1);

$S I=$ number of building occupants expected to experience minor injuries; and

$P_{l}^{M I}=$ percentage of occupants expected to suffer serious injuries within damage level (l). 
The five damage levels are represented as concentric rings, centered at the explosion, with radii equal to the standoff distance associated with each damage level. These blast damage level radii are a function of the blast charge weight; explosive location; blast wall type, height and location; and the building location, geometry and building material. The injury ratio represents the upper limit of reported injury levels within each blast damage level from existing design manuals [23].

\subsection{Calculate psychological impacts}

Survivors of explosive attacks experience a wide range of emotional and psychological disorders. Post-traumatic stress disorder (PTSD) is the best-defined and most studied psychological disorder following terrorist events. Additionally, PTSD is one of the most frequent and debilitating psychological disorders experienced by explosive attack victims [2], [3]. For these reasons, the present model calculates psychological impact as the likelihood that an individual will be diagnosed with PTSD.

The prevalence of PTSD among explosive attack survivors varies by both the individual's degree and type of exposure. Injured survivors, rescue workers, and uninjured bystanders experience PTSD between $30-40 \%, 10-20 \%$, and 5-10\% respectively [2]. The present model uses the upper limit of the reported ranges to calculate the total expected prevalence of PTSD (PTSD), as shown in eqn (4).

The number of injured personnel $(I)$ is equal to the sum of personnel with serious $(S I)$ and minor injuries $(M I)$, as shown in eqn (5). The number of uninjured bystanders $(U)$ is then computed as the number of assigned building occupants $(O)$ minus the number of personnel fatalities and injuries, as shown in eqn (6). The number of rescue workers is a model input based primarily on the attack severity and response capability of the surrounding site or community.

$$
\begin{gathered}
P T S D=\lceil 0.4 I+0.2 R W+0.1 U\rceil \\
I=S I+M I \\
U=O-(F+I)
\end{gathered}
$$

where,

$P T S D=$ number of building occupants expected to be diagnosed with PTSD;

$I=$ number of injured building occupants;

$R W=$ number of rescue workers that respond to the explosive attack; and

$U=$ number of uninjured building occupants.

\section{CASE STUDIES}

This section analyzes four case studies to evaluate the performance of the developed model and demonstrate its distinctive capability to efficiently quantify the physical and psychological impacts of explosive attacks on building occupants.

The selected case studies are intended to highlight the effectiveness of the three aforementioned protection strategies. All four case studies analyze two $80 \mathrm{~m} \mathrm{x} 40 \mathrm{~m}$, two-story office buildings subjected to a $454.5 \mathrm{~kg}$ blast charge weight, which is the design blast charge weight carried in a full-size van [24]. The two office buildings are $40 \mathrm{~m}$ and $80 \mathrm{~m}$ from the explosion, respectively, as shown in Fig. 2 and Fig. 3. Both office buildings are assigned 400 occupants. 


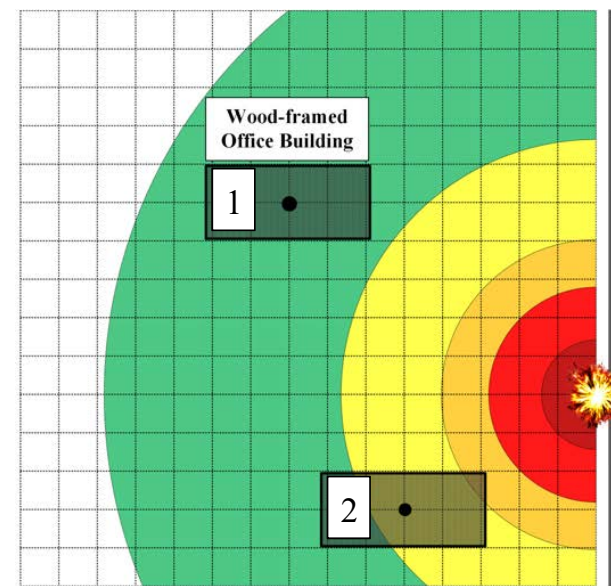

(a)

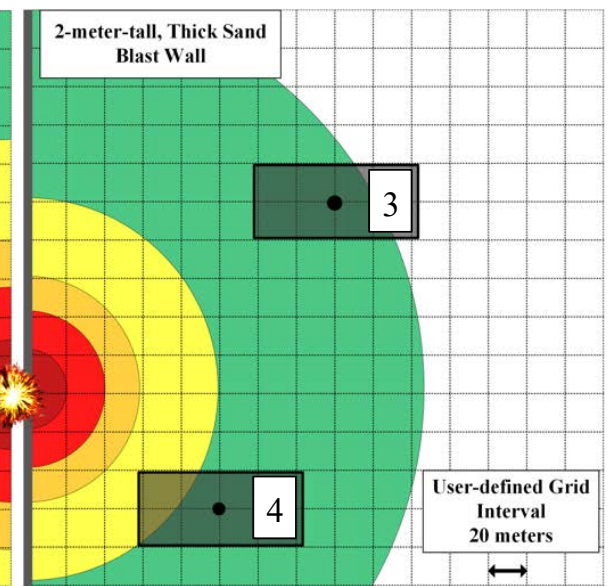

(b)

Figure 2: Damage visualizations for wood-framed office buildings exposed to $454.5 \mathrm{~kg}$ explosive attack. (a) No blast wall; (b) $2 \mathrm{~m}$ tall, thick sand blast wall.

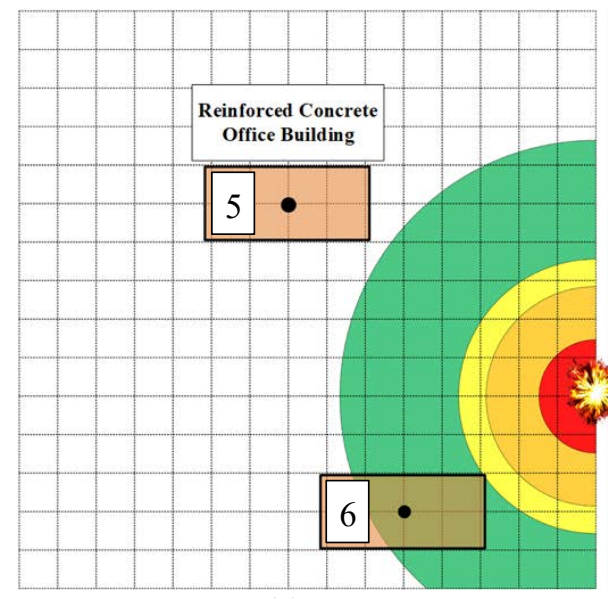

(a)

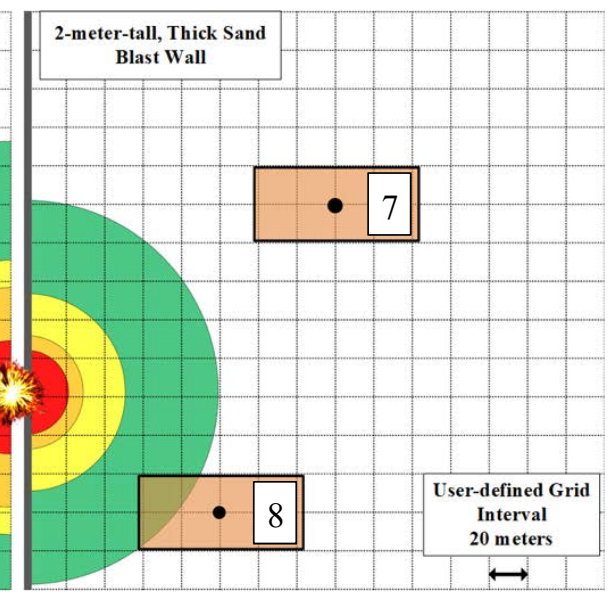

(b)

Figure 3: Damage visualizations for reinforced concrete office buildings exposed to $454.5 \mathrm{~kg}$ explosive attack. (a) No blast wall; (b) $2 \mathrm{~m}$ tall, thick sand blast wall.

A summary of the generated case study data is recorded in Table 1. Case study one analyzed wood-framed office buildings with no blast wall protection. At a $40 \mathrm{~m}$ standoff distance (Building 2), 237 minor injuries, 29 serious injuries, one fatality, and 127 PTSD diagnoses are expected. Doubling the standoff distance to $80 \mathrm{~m}$ (Building 1), without making any other design changes, significantly reduced the number of expected physical and psychological impacts. This scenario resulted in 40 minor injuries, zero serious injuries and fatalities, and only 52 cases of PTSD, mostly suffered by uninjured building occupants.

Case studies two and four evaluated the reduction in expected personal and psychological impacts from constructing a perimeter blast wall to protect wood-frame and reinforced 
concrete (RC) buildings, respectively. Two main conclusions can be drawn from the table results. First, perimeter blast walls are highly effective at reducing blast consequences at close-in distances. For example, the occupants of the unprotected RC building (6) at $40 \mathrm{~m}$ are expected to suffer 128 minor injuries, 11 serious injuries, and 82 cases of PTSD. When the same building is protected by a $2 \mathrm{~m}$ tall, thick sand blast wall, the expected consequences plummet to just nine expected minor injuries, no serious injuries, and 43 cases of PTSD, which are mostly uninjured bystanders. Conversely, at an $80 \mathrm{~m}$ standoff distances, blast wall effectiveness for hardened facilities is negligible (no reduction in consequences), but the wall does provide minor protection for the wood-frame building.

Table 1: Generated case study results.

\begin{tabular}{lccccccc}
\hline $\begin{array}{l}\text { Building } \\
\text { no. }\end{array}$ & $\begin{array}{c}\text { Building } \\
\text { material }\end{array}$ & $\begin{array}{c}\text { Standoff } \\
\text { distance } \\
(\mathrm{m})\end{array}$ & $\begin{array}{c}\text { Blast wall } \\
\text { type }\end{array}$ & MI & SI & F & PTSD \\
\hline 1 & Wood & 80 & - & 40 & - & - & 52 \\
2 & Wood & 40 & - & 257 & 29 & 1 & 127 \\
3 & Wood & 80 & 2 m sand & 30 & - & - & 49 \\
4 & Wood & 40 & 2 m sand & 109 & 9 & - & 73 \\
5 & $\begin{array}{c}\text { Reinforced } \\
\text { concrete }\end{array}$ & 80 & - & - & - & - & 40 \\
6 & $\begin{array}{c}\text { Reinforced } \\
\text { concrete }\end{array}$ & 40 & - & 128 & 11 & - & 82 \\
7 & $\begin{array}{c}\text { Reinforced } \\
\text { concrete }\end{array}$ & 80 & 2 m sand & - & - & - & 40 \\
8 & $\begin{array}{c}\text { Reinforced } \\
\text { concrete }\end{array}$ & 40 & 2 m sand & 9 & - & - & 43 \\
\hline
\end{tabular}

Case study three investigated the third protection strategy - hardening buildings - by comparing the relatively weak wood-frame construction to the more robust RC. At $40 \mathrm{~m}$, the hardened building is expected to have 148 fewer minor injuries, 20 fewer serious injuries, no fatalities, and 54 fewer cases of PTSD. As the standoff distances doubles, the hardened facility loses its clear advantage, resulting in only 10 fewer minor injuries and 3 fewer cases of PTSD. The present model is implemented in Python and all case studies were analyzed using a $2.0 \mathrm{GHz}$ quad-core Intel Core i7 processor with $6 \mathrm{MB}$ of cache memory and 16 GB of synchronous-dynamic random-access memory (SDRAM). The model required an average completion time of 0.23 seconds per case study.

\section{SUMMARY AND CONCLUSIONS}

This paper presented the development of an innovative personnel impact assessment model capable of efficiently quantifying physical and psychological impacts experienced by the occupants of buildings damaged by explosive attacks. The model was developed in three main steps. First, explosive, blast wall, and building inputs parameters were identified and defined. Second, physical impacts, including fatalities, serious injuries, and minor injuries suffered by building occupants were quantified. Third, psychological impacts, measured as expected number of personnel to be diagnosed with PTSD, were calculated for attack survivors. 
Four case studies were analyzed to demonstrate the efficiency of the model and its unique capabilities. The selected case studies highlighted the effectiveness of the three primary blast design protection strategies: (1) maximize the distance between a building and where an explosive can be easily placed; (2) construct perimeter blast walls; and (3) employ blastresistant building materials. The model was able to quantify the expected physical and psychological impacts resulting from a $454.5 \mathrm{~kg}$ explosive attack - the design blast charge weight carried in a full-size van - in an average of 0.23 seconds per case study. Case study results confirm that increasing standoff distance is typically the most effective blast design strategy. Doubling standoff distance decreased the expected number of injured personnel in the wood-frame office building by $86 \%$ and completely eliminated injuries in the reinforced concrete building. Additionally, the increased standoff distance reduced the expected number of PTSD diagnoses in the wood-frame and reinforced concrete office building by $59 \%$ and $51 \%$, respectively. The case studies also verify that blast walls effectiveness increases as the standoff distance decreases. For example, a $2 \mathrm{~m}$ tall, thick sand blast wall decreased the expected number of injured personnel in the wood-frame building by $59 \%$ at a standoff distance of $40 \mathrm{~m}$ compared to a $25 \%$ reduction at $80 \mathrm{~m}$.

The primary contribution of this research is the development of an innovative model that enables designers to efficiently quantify the expected number of fatalities and injuries suffered by building occupants from an explosive attack and predict the extent of psychological impacts among explosive attack survivors. The scope of the developed model can be expanded in future research studies that consider and evaluate additional blast consequences, including economic losses and operational impacts. This model should prove useful to building designers, allowing them to accurately and efficiently evaluate all feasible design alternatives in order to select the design configuration that minimizes the physical and psychological impacts of explosive attacks on building occupants.

\section{ACKNOWLEDGEMENT}

The views expressed in this paper are those of the authors and do not reflect the official policy or position of the United States Air Force, Department of Defense, or the United States government.

\section{REFERENCES}

[1] Dathan, J. \& Kearney, J., Burden of Harm: Monitoring Explosive Violence in 2017. Action on Armed Violence 2018. https://aoav.org.uk/2018/2017-saw-38-increasecivilian-deaths-explosive-violence-new-report-finds/. Accessed on: 21 Jun. 2019.

[2] Neria, Y., Nandi, A. \& Galea, S., Post-traumatic stress disorder following disasters: a systematic review. Psychological Medicine, 38, 2008.

[3] Paz García-Vera, M., Sanz, J. \& Gutiérrez, S., A systematic review of the literature on posttraumatic stress disorder in victims of terrorist attacks. Psychological Reports, 119, pp. 328-359, 2016.

[4] Longinow, A. \& Mniszewski, K.R., Protecting buildings against vehicle bomb attacks. Practice Periodical on Structural Design and Construction, 1, pp. 51-54, 1996.

[5] North, C.S. et al., Psychiatric disorders among survivors of the Oklahoma City bombing. JAMA, 282, pp. 755-762, 1999.

[6] North, C.S. et al., Psychiatric disorders in rescue workers after the Oklahoma City bombing. AJP, 159, pp. 857-859, 2002.

[7] North, C.S. et al., Comparison of post-disaster psychiatric disorders after terrorist bombings in Nairobi and Oklahoma City. The British Journal of Psychiatry, 186, pp. 487-493, 2005. 
[8] Zhang, G., Pfefferbaum, B., Narayanan, P., Lee, S., Thielman, S. \& North, C.S., Psychiatric disorders after terrorist bombings among rescue workers and bombing survivors in Nairobi and rescue workers in Oklahoma City. Annals of Clinical Psychiatry, 28, pp. 22-30, 2016.

[9] Galea, S. et al., Psychological sequelae of the September 11 terrorist attacks in New York City. New England Journal of Medicine, 346, pp. 982-987, 2002.

[10] Schlenger, W.E. et al., Psychological reactions to terrorist attacks: Findings from the national study of Americans' reactions to September 11. JAMA, 288, pp. 581-588, 2002.

[11] Gabriel, R. et al., Psychopathological consequences after a terrorist attack: An epidemiological study among victims, the general population, and police officers. European Psychiatry, 22, pp. 339-346, 2007.

[12] Vázquez, C., Hervás, G. \& Pérez-Sales, P., Chronic thought suppression and posttraumatic symptoms: Data from the Madrid March 11, 2004 terrorist attack. Journal of Anxiety Disorders, 22, pp. 1326-1336, 2008.

[13] Mallonee, S., Shariat, S., Stennies, G., Waxweiler, R., Hogan, D. \& Jordan, F., Physical injuries and fatalities resulting from the Oklahoma City Bombing. JAMA, 276, pp. 382-387, 1996.

[14] Sasser, S.M., Sattin, R.W., Hunt, R.C. \& Krohmer, J., Blast lung injury. Prehospital Emergency Care, 10, pp. 165-172, 2006.

[15] Cave, K.M., Cornish, E.M. \& Chandler, D.W., Blast injury of the ear: Clinical update from the global War on Terror. Military Medicine, 172, pp. 726-730, 2007.

[16] Morley, M.G., Nguyen, J.K., Heier, J.S., Shingleton, B.J., Pasternak, J.F. \& Bower, K.S., Blast eye injuries: A review for first responders. Disaster Medicine and Public Health Preparedness, 4, pp. 154-60, 2010.

[17] Ataei, H. \& Anderson, J.C., Mitigating the injuries from flying glass due to air blast. Sixth Forensic Engineering, pp. 133-142, 2012.

[18] Khalafallah, A. \& El-Rayes, K., Minimizing construction-related security risks during airport expansion projects. Journal of Construction Engineering and Management, 134, pp. 40-48, 2008.

[19] Said, H. \& El-Rayes, K., Optimizing the planning of construction site security for critical infrastructure projects. Automation in Construction, 19, pp. 221-234, 2010.

[20] Li, Z., Shen, W., Xu, J. \& Lev, B., Bilevel and multi-objective dynamic construction site layout and security planning. Automation in Construction, 57, pp. 1-16, 2015.

[21] Schuldt, S. \& El-Rayes, K., Optimizing the planning of remote construction sites to minimize facility destruction from explosive attacks. Journal of Construction Engineering and Management, 144, p. 04018020, 2018.

[22] Schuldt, S. \& El-Rayes, K., Quantifying blast effects on constructed facilities behind blast walls. Journal of Performance of Constructed Facilities, 31, p. 04017027, 2017.

[23] Department of Defense (DoD), DoD minimum antiterrorism standards for buildings. UFC 4-010-01, Washington, DC, 2012.

[24] Federal Emergency Management Agency (FEMA), Reference manual to mitigate potential terrorist attacks against buildings. FEMA-426/BIPS-06 Edition 2, Washington, DC, 2011. 